July 1985

\title{
Some reflections on Termination: Transference and Countertransference
}

Frederick L. Becker, Jr, MD

Thomas Jefferson University Hospital

Follow this and additional works at: https://jdc.jefferson.edu/jeffjpsychiatry

Part of the Psychiatry Commons

Let us know how access to this document benefits you

\author{
Recommended Citation \\ Becker, Jr, MD, Frederick L. (1985) "Some reflections on Termination: Transference and \\ Countertransference," Jefferson Journal of Psychiatry. Vol. 3 : Iss. 2 , Article 5. \\ DOI: https://doi.org/10.29046/JJP.003.2.002 \\ Available at: https://jdc.jefferson.edu/jeffjpsychiatry/vol3/iss2/5
}

This Article is brought to you for free and open access by the Jefferson Digital Commons. The Jefferson Digital Commons is a service of Thomas Jefferson University's Center for Teaching and Learning (CTL). The Commons is a showcase for Jefferson books and journals, peer-reviewed scholarly publications, unique historical collections from the University archives, and teaching tools. The Jefferson Digital Commons allows researchers and interested readers anywhere in the world to learn about and keep up to date with Jefferson scholarship. This article has been accepted for inclusion in Jefferson Journal of Psychiatry by an authorized administrator of the Jefferson Digital Commons. For more information, please contact: JeffersonDigitalCommons@jefferson.edu. 


\title{
SOME REFLECTIONS ON TERMINATION: TRANSFERENCE AND COUNTERTRANSFERENCE
}

\author{
FREDERICK L. BECKER, JR., M.D.
}

\section{INTRODUCTION}

Nearing the completion of my psychiatric residency, I ingenuously told my supervisor that I needed to know the steps of termination in therapy with patients. On the surface, this request reflected an awareness of the issues at hand and their importance. Beneath lay ambivalence and countertransference anxiety. For the graduating resident, time ordinarily invested in thought and study fills with practical considerations of job hunting and starting a practice. The resident's own unresolved and unsettling separation issues can further push aside therapeutic considerations for his patients. Termination, the art of the veteran therapist, becomes an unwelcome task at this time of professional passage when anything codifying professional identity is sought. In the unfortunate sequence of most residencies, this can be the first experience with forced termination of therapy.

Forced termination is also a neglected topic within termination literature: a stepchild absent from standard psychotherapy texts from Colby to Tarachow. Weigert (1) and many others expound a necessary mutuality between patient and therapist before termination can be set. Any prematurity on the therapist's part, by definition, sets up a forced situation with its concommitant transference reactions and may be initiated by unintentional countertransference reactions.

In reference to character analysis, Freud (2) doubted if even deep analysis could prevent a return of neurotic symptoms under the pressures of everyday life. The issue here becomes not whether treatment is terminable; but rather, one of understanding transference and countertransference.

Supervision and the resident's own therapy can make difficult terrain into a crucial learning experience. I share my experience with just one patient and my imperfect understanding of a complex interaction, in light of termination literature.

\section{THE PATIENT}

J.B. is a twenty-eight-year-old wife and mother haunted by a variety of stroke like somatic complaints since her maternal aunt died of a stroke one year previously. Most recently, she has developed a knife phobia, particularly near her two children, and a disorganizing anxiety and fear of death when alone, precipitating panic attacks and marked social withdrawal.

Her early childhood was chaotic - replete with themes of maternal dependency and separation. She was never sure who was her biologic father. She spent her

Dr. Becker wrote this paper as a fourth-year resident. 
preschool years with her maternal aunt on weekdays, and with her mother and alcoholic father on weekends, witnessing much physical violence between them. She was not physically abused herself, but she recalled during a parental fight at the age of five drawing a knife on her father to protect her mother. Separation and divorce ensued shortly thereafter.

She was seriously incapacitated during most of her elementary school years with rheumatic heart disease, missing months of school. Her mother cared for her and tutored her while working as a nurse to support them. Her mother eventually married a man who became a stable "real" father for J.B.

Much of her adolescence was spent as caretaker of her mother who had a myocardial infarction, and her divorced father, who lived nearby and had become bedridden from diabetes and alcoholism. He died when J.B. was sixteen years old. Subsequently she married after a relatively short, impersonal engagement. Her first child, a girl, became the focus of her tense overprotectiveness. Her second child, a boy, along with his father, took a more distant orbit from the mother-daughter nucleus.

The inception of somatic symptoms occurred with the death by stroke of her maternal aunt. At the time both the patient and her daughter had started school. The patient who was studying for a nursing degree, soon failed the semester and dropped out.

\section{THE TRANSFERENCE AND COURSE OF THERAPY}

That which doesn't kill you makes you stronger.

Nietzsche

The course of therapy was marked by two phases divided by setting a termination date at roughly the half-way point, or nine months, into therapy. During the first phase a strong maternal transference crystallized, adulterated by medication administration. I started her on imipramine for her panic attacks and added a low dose major tranquilizer for the disorganizing anxiety. We met twice weekly.

Her apprehensive demeanor restricted her participation in the therapeutic process, creating a considerable resistance. She was afraid to think or feel. Her phobic symptoms and panic attacks remitted. During this beginning phase, her tenacious dependency parallelled a counterdependent desire to be well and end therapy within a month's time. She took therapy and medications religiously, while diligently struggling not to need either.

Her fear of my interventions was examined tediously, allowing exploration of her mother's overindulgence and unpredictable neglect. Slowly and incompletely she identified her anger toward her mother, even slower her anger toward her children, specifically her daughter. As the mother-daughter symbiotic tangle loosened, she began to understand the role her dependency played in exacting attention from and maintaining control over her family. Her fear of being alone decreased and she no longer needed an escort to function.

Her anxiety over the harm which would befall her children while at school 
diminished as their summer vacation approached. I brought up my departure, which was to occur in nine months, and discussed with her the alternative of transfer to another doctor's care if it became necessary. With the introduction of a termination date, her somatic symptoms, including dysphagia, returned. She was also afflicted with chest palpitations. We examined the symptoms in light of secondary gain of the sick role, exacting care from me and prolonging therapy. Her palpitations continued. I referred her to an internist for a physical exam. Holter monitor and blood studies were performed; and all were normal. She then had a dream, the first brought into therapy: I was drawing blood from her arm. She awoke from the dream, frightened she would be sucked dry.

She associated to my probing questions and her frequent frustration at having no response. In one session, she angrily reprimanded me for "making (her) feel this way-like in a whirlpool." She identified her guilty feelings for the fantasized act of driving her father away at the age of five. She began to share feelings of exploitation by men. For the first time, information arose regarding her rape in adolescence and the forced incest with her older male cousin when she was five through eight years old.

Positive feelings for her father were remembered. Soon, erotic feelings for me were manifested indirectly in discussions occurring outside therapy. The feelings were only tentatively acknowledged face-to-face. Also, for the first time, we explored her sex life with her husband and her feelings of being sexually undesirable to him. Her symptoms had once more diminished.

Therapy was cut back to once a week and an attempt was made to wean the major tranquilizer. Her payments fell behind. She was afraid to confront her husband, who wrote the checks, like a dependent child needing my protection and wanting it free. A minor incident aroused her annoyance with me and she half-heartedly connected her frustration to anger at my departure. She associated to the feeling of being in a whirlpool and the disorganized emptiness she had experienced with her panic attacks when left alone.

A six month follow-up from her new therapist revealed an unremitting idealized transference to me. She had become boring to him; she seemed to "just want him to be there to listen," providing a toilet function. She continued to exhibit a low level generalized anxiety with no further discrete panic attacks. He was anticipating seeing her in medication clinic only. Her medication continued to provide her with the attachment to an omnipotent giver, supplying her deeper narcissistic needs.

Firestein (3) and others find setting an actual termination date provides a real event precipitating strong affective reactions manifested in dreams, fantasies and concrete plans in therapy. Weiss (4) speaks of special events which, although experienced by the patient as intrusions by the real person of the therapist, nonetheless evoke strong transference affects. The stimulation of the dream and its content following the intrusive medical consultation highlights intensification of the issues of trust and giving. The dream became a gift demarcating the end of an emotionally constipated phase, heralding a richer involvement-perhaps a gift enticing me to stay from a patient unable to yield her dependency.

Freud (2), in his case of the Wolf Man, describes setting a termination date as a 
technical ploy, only after which decisive case material became available. Orens (5) also discusses termination, giving an impetus to therapy in his case of a woman with post-partum depression. He stresses exploring the meaning analysis has for the patient and the meaning of its end. For J.B., the introduction of a termination date shifted the focus of therapy from the overwhelming dependent relationship with her mother to the issues of separation and loss of her father. It also broke through her strong affective isolation impeding her progress in therapy. The special unconscious meaning termination represented within the sadomasochistic scheme was insufficiently explored, as will be discussed later.

Lower (6) elegantly examines the psychotherapy of neurotic dependency in patients who, despite their sick presentations, evidence resilient egos. Their sadistic impulses characterizing a drive for mastery and autonomy are repressed along with the conflictual sadism associated with oedipal wishes to rival and destroy. They regress to dependency and passive-aggressive control. J.B., in her choice of mother over father, knife raised above her head, made a choice of safe dependency over dangerous incestuous wishes. Instead of desiring me, she wanted to merge with me. Lower warns of well intended therapeutic maneuvers, including pharmacotherapy, promoting chronicity in these patients. He believes termination should be set months in advance and firmly kept. If necessary, the introduction of a second therapist can aid exploration of oedipal issues.

Regarding symptom recurrence, Firestein (3) goes on to caution against prematurely attributing to much importance to the patient's preconscious ploy to coerce the therapist into prolonging therapy. The symptoms of J.B. continued and no doubt had roots specific to underlying separation conflicts. Through regression they became manifest.

To Sher (7), transfer of a patient between two therapists becomes an interesting therapeutic triangle: one which can bind the patient. To improve under the care of the new therapist would be disloyal to the former therapist and to decompensate defies the rescuer therapist. To compromise and remain unchanged defeats all members of the triangle, as seen with J.B.

Of course the optimum result is identification with the therapist's analytic ego. As Rangell (8) states: "This lays ground work for the self analysis that continues in the post-termination phase of therapy." Transfer to another therapist may temporarily postpone this possibility. Sher (7) points out the new therapist has the initial task of helping the patient resolve the sorrow and rage usually present with loss of the former therapist.

Reider (9) characterizes a particular transference to institutions in a group of schizoid patients with multiple therapist transfers. The transference magically and interminably supplies enough narcissistic needs to secure a continuing parasitic relationship to the institution, forming a primary resistance to therapy with an individual therapist. Similarly, an idealized transference to a previous therapist can be a strong resistance, as in the above case of J.B.

Some patients with apparently healthy premorbid personalities can become "sticky" at discharge from therapy or, with the termination of a stable holding 
environment, decompensate, as Olsen and Biddinger (10) describe. They postulate these patients never attain Erikson's stage of generativity and instead lead relatively stable lives with attachment to a spouse or even an institution, be it clinical, educational or military. Separation-individuation issues only arise upon disruption of the stable holding environment.

Early recognition of separation-individuation issues and previous significant object losses of the patient can prepare the therapist for the surprises often inherent in the period of forced termination and sensitize him to the awareness of countertransference stirrings.

\section{THE COUNTERTRANSFERENCE}

What we call the beginning is often the end And to make an end is to make a beginning. The end is where we start from.

T.S. Eliot

The dearth of literature on forced termination is more surprising considering the frequency of its occurrence in training programs. Significantly, most reports are from the hands of supervisors. Repression from the therapist's own guilt for abandonment of patients along with the time consuming practical considerations of residents at graduation contribute to the neglect.

Pumpian-Mindlin (11) opines countertransference as the most important factor at this time. He lists the three essential elements as: the emotional investment in the patient, the termination anxiety in the therapist, and, lastly, the goals set by the therapist for what he wished to accomplish.

Firestein (3) lists at least two countertransference requirements to ensure proper termination: the therapist's gratification in therapy functions must be independent of the personality of a specific patient, and he should be distant in time from significant termination experiences of his own.

Keith (12) outlines the "transfer syndrome" in patients and various countertransferences which occur in resident-therapists. Among them is the reaction of selfdenigration and the denial of one's importance to the patient. Also, procedural defenses may arise, such as preoccupation with the mechanisms of transfer at the expense of exploring the emotional reaction of the patient. The therapist may forget to record process notes or get caught up in scheduling appointments, unpaid bills, et cetera.

In the preceeding case, patient termination was coincident with a forced relocation and termination of my own therapy for fulfillment of a military obligation. In my own therapy, issues of separation from an overprotective and insecure mother, the wish to flee, fears of incest and castration, and guilt for abandonment were clarified. J.B. became freer with her feelings and unconscious desires for me as I became freer to hear them and feel my own desires for her.

My own anger over my forced relocation was impotently expressed, displaced and acted out in a relationship outside my therapy before a final working through occurred. 
My own repressed and displaced sadism prevented a complete examination of the sadomasochistic roles played out with the medication and the medical consultation. Supervision on this patient ended by mutual agreement over one month before the forced termination date, evidencing further denial. However, I continued to record process notes.

In one study, it was found that difficulty separating from patients was proportionate to the reluctance of the therapist to move on to his next installation (11). Those residents anxious and insecure about starting private practice had serious difficulties terminating or transferring patients-more so than those residents who had previous experience in private practice.

Schiff (13) notes a therapist's unwillingness to terminate can promote patient regression. Thus, transfer rather than termination can thwart a patient's move toward autonomy and reminds one that mental normality, whatever that may be, is not the gauge used for treatment termination. Remission of presenting symptoms is a more likely and realistic gauge.

The transfer of patients, although more passive and less challenging than termination, has other difficulties. The transferring therapist may feel his results by which he is judged are exposed. Private ambition may attempt to compensate for any narcissistic wounds otherwise received. My subjective perception of J.B.'s improvement, despite the dependent standstill which evolved, resulted from embarrassment and discouragement of ending with the unfulfillment of unrealistic treatment goals.

Weigert (1) expounds: "The resolution of the countertransference permits the analyst to be emotionally freer and spontaneous with the patient." She underscores the "emotional galvanometer of empathic countertransference" as being a refined instrument for determining progress and the need for termination. With overidentification and overactivity the galvanometer can go awry. My active intrusions with medication and medical consultation proscribed who would be dependent in the therapy and who would not, and made later exploration of the negative transference more difficult.

Difficulties in separating can appear throughout the course of therapy. How an individual session is ended and what is said can be clues, along with the assiduous recording of process notes. Sometimes a failure to recognize the patient's capacity to work outside the session or post-termination can lead, in the former case, to pushing during the session to get things accomplished and, in the latter case, to unnecessary transfer.

Lipton (14) believes the therapist to be especially vulnerable to self-gratification during termination, unless strict adherence to the analytic process continue to the last minute. The tendency toward an interpersonal relationship increases as termination approaches. He also recognizes patients who "so frequently look forward to some form of transference gratification at the conclusion and tend to use this period as an enclave for fantasies."

Overidentification and the therapist's own separation issues can both create a countertransference battlefield on which is waged a war of control: the fear/wish to stay/stand or walk away. An unfortunate outcome can be the practice of maintaining patients in therapy until program graduation, a frequent occurrence in training 
programs, then the recommendation is made for a trial therapeutic termination, out of the therapist's sloppy neglect of treatment goals or his ill-conceived unilateral maneuvering carried out at his own convenience.

External realities like cultural determinants may also impinge upon the decision to terminate. The prevalent instant-on mentality spawned by technological advances make lengthy processes seem impractical or even unnecessary. Dwindling third party resources further narrow the possibilities of therapy available to the general population. Thus, the newer brief psychotherapies flourish on the spectrum from lengthy psychoanalysis or multiple analyses to the faster behavioral and hypnotic therapies. These brief therapies can be operative models for forced termination in at least the sense of modified, even truncated, treatment goals and the patient's subsequent mourning of unfulfilled wishes-specifically, the wish for cure. With the longer therapies, one inevitably speaks of transference issues with termination. In the brief therapies, the transference is no longer the method of cure. Here, countertransference separation anxieties and practical exigencies can entice the beginning therapist to choose quick cure over therapeutic depth, structured ending over ambiguity of termination and treatment goals.

No doubt one's view of termination intimately intertwines with one's stage of growth and experience. Ferenczi (15) in his earlier years believed in setting the termination date unilaterally, upon the formation of the transference neurosis. In his later years, he changed his mind: "As long as a patient wants to come, he belongs in analysis." It would be of interest to investigate longitudinally the changing views of particular therapists as they gain experience and draw closer themselves to the ultimate termination. Perhaps more than therapeutic experience qualifies termination as the art of the veteran. A hormonal and libidinal ebb makes closure an issue and death more than a verbal shadow of denial.

Certainly, both termination of therapy and death are metaphors for change. In the former, the unconscious elements of transference slip back into random life more organized, yet no longer confronted by a countertransference dependent upon them for its existence. In the latter case, there is the final dissolution of these elements.

\section{CONCLUSION}

In his familiar chess game analogy, Freud described the opening and closing moves in therapy, as well as the infinite variety of moves in between. In forced termination or patient transfer, it is well to study the effects of this special event on both transference and countertransference, as the moves may not be as familiar as one thought. A rigidity of outlook as to what is to be expected can rob therapy of spontaneity otherwise achieved through literature review, a supervisor's guidance, one's own therapy, and ultimately, simply listening to the patient. To leave this process to chance, as occurs in many training programs, can rob the resident-therapist of a crucial learning experience. Perhaps the answer to the final question-to end or not to end-can be bought by one's obsessive need to tie up loose ends, to search for a termination formula as neatly wrapped and unambiguous as a paper on termination. 


\section{REFERENCES}

1. Weigert E: Contribution to the problem of terminating analysis. Psychoanal Quart 21: 466-467, 473, 1952

2. Freud S: Analysis terminable and interminable. Int J Psychoan 18: 373-405, 1937

3. Firestein SK: Termination in Psychoanalysis. New York, International Universities Press, 1970

4. Weiss S: The effect on the transference of "special events" occuring during psychoanalysis. Int J Psychoan 56: 69-75, 1975

5. Orens M: Setting a termination date, an impetus to analysis. J Am Psychoan As 3: 651-665, 1955

6. Lower: Psychotherapy of neurotic dependency. Am J Psych 124: 514-520, 1967

7. Sher M: The process of changing therapists. Am J Psychother 24: 278-286, 1970

8. Rangell L: Problems of termination in the analysis of adults (panel discussion). Report by Firestein SK. J Am Psychoan As 171: 222-237, 1969

9. Reider N: A type of transference to institutions. Bull Men Clin 17: 58-63, 1953

10. Olsen HE, Biddinger JE: Interminable treatment in patients who appear healthy. Hosp Com Psych 35: 710-714, 1984

11. Pumpian-Mindlin E: Comments on technique of termination and transfer in a clinic setting. Am J Psychoth 12: 455-464, 1958

12. Keith C: Multiple transfers of psychotherapy patients. Arch Gen Psych 14: 185-189, 1966

13. Schiff S: Termination of therapy. Arch Gen Psych 6: 93-98, 1962

14. Lipton S: The last hour. J Am Psychoan As 9: 325-330, 1961

15. Ferenczi $\mathrm{S}$ : The problem of termination in psychoanalysis, in Final Contributions to Psychoanalysis. New York, Basic Books, 1955 